(อ) interface

comunicação, saúde, educação

https://www.interface.org.br

elSSN 1807-5762

\title{
Artigos
}

\section{Atividades socioculturais como interface de bem-estar emocional e de prevenção da transmissão da Covid-19 em estruturas residenciais para pessoas idosas}

Sociocultural activities as an interface between emotional well-being and the prevention of Covid-19 transmission in nursing homes (abstract: p. 17)

Actividades socioculturales como interfaz de bienestar emocional y de prevención de la transmisión de la Covid-19 en estructuras residenciales para ancianos (resumen: p. 17)

Jenny Gil Sousa(a)

$<$ jenny.sousa@ipleiria.pt> (a) Escola Superior de Educação e Ciências Sociais, Politécnico de Leiria, CICS.NOVA.IPLeiriaiACT, CI\&DEI. Campus 1, Rua Dr. João Soares, Apt. 4.045. Leiria, Portugal. 2411-901.

Em Portugal, cerca de 40\% das mortes por Covid-19 aconteceram em instituições para idosos, passando a exigir delas práticas institucionais de isolamento social, com graves repercussões na Saúde Mental dos residentes. Com esta pesquisa, qualitativa e exploratória, pretendeu-se perceber se, em período de pandemia, a realização de atividades socioculturais, por meio da animação de idosos, pode funcionar como interface do bem-estar emocional dos residentes e da prevenção da transmissão da Covid-19, segundo os técnicos que desempenham o papel de animadores. São, assim, apresentados os resultados obtidos com base na análise de conteúdo da entrevista semiestruturada aplicada a 16 profissionais que trabalham em estruturas residenciais para idosos, de norte a sul de Portugal Continental, tendo os dados evidenciado que a realização de atividades socioculturais surge como elemento determinante de bem-estar e de qualidade de vida daqueles que vivem nas instituições.

Palavras-chave: Velhice. Institucionalização. Covid-19. Intervenção sociocultural. Bem-estar emocional. 


\section{Introdução}

O ano 2020 ficou marcado como o ano em que a Covid-19 - nome atribuído pela Organização Mundial da Saúde e que resulta das palavras "Corona", "Vírus" e "Doença" com referência ao ano de surgimento (2019) - assolou todo o planeta. Essa doença infecciosa, provocada pelo novo coronavírus SARS-COV-2, pode ter diversas consequências nefastas, entre elas pneumonia grave com insuficiência respiratória aguda, falência renal e de outros órgãos e eventual morte, conforme se explica no site do Serviço Nacional de Saúde de Portugal ${ }^{1}$.

Algo que começou na China rapidamente chegou a todo o mundo. E, inevitavelmente, emergiu a preocupação: “este vírus representa maior risco para quem?”. Em 2020, o grupo populacional mais vulnerável e que apresentava maior letalidade referente à Covid-19 era o das pessoas idosas, designadamente os detentores de doenças crônicas e de maior vulnerabilidade às doenças infectocontagiosas ${ }^{2}$. Os dados epidemiológicos, publicados pela Direção-Geral da Saúde ${ }^{(b)}$ portuguesa durante o mês de junho de 2020, revelaram que cerca de $40 \%$ das mortes por Covid-19 aconteceram em lares ou estruturas residenciais. Isto é, atingia majoritariamente os que detinham uma saúde mais frágil e que, muitas vezes, se encontravam também em situação de vulnerabilidade social.

Assim que ocorreu a primeira morte em uma estrutura residencial, as instituiçóes de apoio a pessoas idosas viram-se obrigadas a fazer profundas modificaçôes na sua forma de funcionamento, principalmente nas dinâmicas de trabalho e no modo de relacionamento entre as pessoas. Tudo mudou para impedir a entrada da Covid-19. Nesse quadro de alteração profunda, em que tudo se faz para que o vírus não entre, como fica o bem-estar social e emocional das pessoas idosas que lá vivem? Que lugar pode tomar a realização de atividades socioculturais em um contexto de sobrevivência e de luta contra um inimigo sem rosto?

As atividades socioculturais, que neste estudo se consubstanciam nas práticas de animação de idosos, dizem respeito a ações de diferentes naturezas: quotidiano/prático (atividades associadas a tarefas da rotina diária, como apoio na lavandaria, tratar da horta/jardim ou realização de trabalhos manuais), sociais (atividades que promovem a sociabilidade, o contacto e as relações interpessoais, como jogos de grupo, festas e convívios), artísticas (exploração de atividades ligadas ao teatro, à fotografia, às artes plásticas, à dança), intelectuais/formativas (atividades de raciocínio e lógica mental, como leitura, jogos, formação) e atividades espirituais/religiosas (frequentar locais de culto, assistir a cerimônias religiosas, rezar) ${ }^{3}$.

Assim, e diante do exposto, foi realizada uma pesquisa de natureza qualitativa e exploratória, no âmbito dos Estudos Culturais ${ }^{4}$, que teve como principal objetivo perceber se, em período de pandemia, a realização de atividades socioculturais de animação de idosos pode funcionar como interface do bem-estar emocional dos residentes e da prevenção da transmissão da Covid-19, segundo os técnicos que desempenham o papel de animadores.

De uma forma mais operativa, pretendeu-se identificar os constrangimentos ao desenvolvimento das atividades socioculturais no contexto específico atual e conhecer as mais-valias desse tipo de intervenção no bem-estar dos residentes, bem como o seu papel na prevenção e no controle da Covid-19 nas instituições.

\footnotetext{
(b) Disponível em: https:// covid19.min-saude. pt/327-obitos-por-covid19-ocorreram-em-lares-deidosos/. Acessado em: 22 jun. 2020.
} 
A relevância desse estudo se consubstancia no fato de permitir conhecer uma realidade inédita em Portugal, originada pela Covid-19, no que se refere ao modo como a pandemia influencia as respostas institucionais que estão sendo dadas, até o momento, no nível da promoção da qualidade de vida nas estruturas residenciais de apoio a pessoas idosas. Para além disso, provoca a reflexão em torno da práxis quotidiana dos profissionais de animação, nomeadamente sobre as estratégias utilizadas e sua forma de implementação, no fomento do bem-estar emocional e na manutenção da Saúde Mental dos residentes.

\section{Velhice e institucionalização em pleno século 21}

Depois de todos os avanços realizados nos últimos séculos, mas mais acentuadamente no século 20, é no século 21 que se verifica a maior esperança média de vida de sempre e os números revelam que as sociedades têm hoje mais pessoas idosas do que alguma vez tiveram 5 .

Esse fenômeno se tornou um tema de significativa vitalidade no contexto mundial, em que Portugal não é exceção. Com efeito, Portugal é atualmente um dos países com maior tendência de envelhecimento de toda a Europa, encontrando-se na $4 \underline{a}$ posição no ranking dos países mais envelhecidos ${ }^{6}$.

Emergiu, no mapa sociocultural dos diversos países, designadamente em Portugal, uma nova ordem social que, embora mereça ser celebrada, acaba por colocar um conjunto de novos desafios nos mais variados domínios 5 . Com uma pirâmide invertida, ou seja, com mais pessoas na idade adulta avançada do que na infância, as preocupaçóes centram-se agora na implementação de estratégias para que os mais velhos possam viver com qualidade e incluídos socialmente ${ }^{7,8}$. Isso significa viver em um novo paradigma, sem estereótipos, nem preconceitos, respeitando a heterogeneidade do grupo e a singularidade de cada um, uma vez que os percursos de envelhecimento são amplamente marcados por diferentes fatores como as questóes culturais, as condiçóes econômicas, a saúde física e mental, as redes sociais de pertença e de apoio, a satisfação das necessidades psicológicas, entre outros ${ }^{9-11}$.

Em linha com o apresentado até ao momento, pensar o papel da velhice, nos dias de hoje, é admitir que existem inúmeras dimensóes que influenciam o bem-estar dos mais velhos, designadamente os fatores ambientais, culturais e sociais, demonstrando que existem diferentes formas de envelhecer e que a trajetória vital, o autoconceito, as experiências culturais e os apoios sociais são primordiais, ${ }^{911-13}$.

Embora a preferência dos indivíduos, à medida que envelhecem, seja continuar a viver na sua casa e na comunidade de pertença ${ }^{8,14}$, a verdade é que para um grande número de pessoas isso não é possível. São inúmeras as razões que condicionam a manutenção nas suas residências (falta de recursos monetários, de espaço físico e/ou afetivo junto dos familiares, de apoio para executar as tarefas básicas do dia a dia ou motivos médico-sociais) e que levam à decisão da institucionalização a título permanente. 
Em Portugal, as respostas sociais dirigidas à população idosa são tuteladas pelo Estado, centralizadas pela Segurança Social, que trabalha em parceria com as Instituiçóes Particulares de Solidariedade Social. A Estrutura Residencial é a modalidade mais antiga de ajuda aos sujeitos idosos (principalmente para aqueles que se encontram em maior vulnerabilidade de saúde, social e econômica) e a resposta social com representação mais significativa ${ }^{6}$.

As Estruturas Residenciais, conforme se pode ler na página web da Segurança Social ${ }^{15}$, são uma resposta social destinada a alojamento coletivo, de utilização temporária ou permanente para pessoas de idade adulta avançada, e apresenta como principais objetivos proporcionar serviços permanentes e adequados à problemática biopsicossocial das pessoas idosas; contribuir para a estimulação de um processo de envelhecimento ativo; criar condiçóes que permitam preservar e incentivar a relação intrafamiliar e potenciar a integração social.

Nessa situação, facilmente se reconhece que a missão desse tipo de instituições é profundamente ampla, indo para além da satisfação das necessidades básicas, como alimentação e higiene. Alinhado com aquilo que é preconizado pela Organização Mundial de Saúde $(\mathrm{OMS})^{16}$ e pelos vários organismos nacionais, nomeadamente a Direção-Geral de Saúde ${ }^{17}$ por meio da Estratégia Nacional para o Envelhecimento Ativo e Saudável 2017-2025, essas instituiçóes têm hoje como pano de fundo o paradigma do envelhecimento ativo, em uma ótica de proteção dos que são mais vulneráveis e de promoção da sua inclusão e integração em todos os aspetos da vida da comunidade. Nessa equação são extremamente importantes as relações afetivas gratificantes e a criação de relacionamentos satisfatórios que conduzam ao aumento do bem-estar emocional ${ }^{6-8}$.

Esses são os desafios das Estruturas Residenciais do século 21: criar ambientes físicos e sociais potenciadores da integração, da proteção e da inclusão das pessoas idosas, quer pela remoção de barreiras à participação, quer pela compensação da perda de capacidades ${ }^{17}$.

Contudo, em pleno período pandêmico, as estruturas residenciais representam o principal fator de risco para a morbimortalidade da infeção por Covid-19, uma vez que reúnem todos os elementos de risco. Assim, foram priorizadas medidas preventivas e de controle da infeção, em uma tentativa de redução do risco de contaminação que passou pela restrição humanizada de visitas, controle de acesso aos trabalhadores, distanciamento social, maior separação entre os trabalhadores e os idosos nas atividades não relacionadas ao cuidado ${ }^{18}$. Essas alteraçóes acabaram por se constituir em elementos estressantes e geradores de ansiedade, com grande impacto na Saúde Mental dos indivíduos residentes ${ }^{19}$. Diante desses aspetos, como é que se podem manter boas condições de Saúde Mental? Qual é o papel que pode tomar a realização de atividades socioculturais? 


\section{A intervenção sociocultural em estruturas residenciais: a animação de idosos}

A intervenção sociocultural, no contexto específico das estruturas residenciais, assume diversas formas, sendo uma delas a animação de idosos. A animação de idosos detém um papel importante na promoção da saúde ao ser uma metodologia que trabalha com a intenção de manter as pessoas idosas inseridas na sociedade e dela participarem ativamente. Tendo por base uma abordagem psicossocial dos problemas, a animação tem como principal preocupação os fatores sociais da saúde, trabalhando na incidência que esses elementos detêm nos indivíduos e nas comunidades, dirigindo a ação para a saúde e não para a doença ${ }^{20,21}$. Nesse processo, desenvolvem-se inúmeras áreas que trabalham objetivos específicos: lúdicos, criativos, expressivo-comunicacionais, participativos e evocativos e de estimulação ${ }^{22}$. Esses objetivos se concretizam em atividades de diversos âmbitos, tal como já foi referenciado em momento anterior deste trabalho: atividades quotidianas/práticas; atividades sociais; atividades artísticas; atividades intelectuais/formativas; e atividades espirituais/religiosas ${ }^{3,21}$.

Tal como se pode verificar, as práticas de animação de idosos não situam o indivíduo em uma dimensão exclusivamente individual, uma vez que têm em linha de conta as dimensões sociais e culturais. Assim, o bem-estar e a Saúde Mental, encaradas em uma perspetiva pluridisciplinar de adaptação-inadaptação, encontram na sua base a interação entre fatores biológicos e sociais. Nesse cenário, a animação de idosos, como estratégia potenciadora de competências pessoais e sociais de bem-estar emocional, prevê o desenvolvimento do indivíduo, integrando-o em um contexto de intervenção social ${ }^{21,23,24}$. Contudo, atente-se que tão importante como a cultura colaborativa é o trabalho individual e em pequenos grupos, devendo o animador evitar a massificação das atividades socioculturais ${ }^{22}$.

A animação de idosos preconiza o desenvolvimento de competências pessoais e sociais e, especialmente em contexto institucional, constitui-se em uma metodologia privilegiada de atuação nos diversos campos da qualidade de vida dos mais velhos, funcionando como um estímulo permanente da vida mental, física e afetiva ${ }^{11,20,25}$. Conforme explica Juliana Quintero ${ }^{26}$, a animação de idosos é uma metodologia que permite o movimento entre várias ações na resposta às diferentes necessidades do adulto em idade avançada. Por ter um fundamento pedagógico, possibilita a realização de inúmeras atividades aos mais variados níveis, em que as relações interpessoais são fundamentais. Nessa conjuntura, a animação demarca-se como suporte de comunicação que privilegia o aspeto relacional, constituindo-se em um elemento determinante da qualidade de vida da instituição.

Por isso mesmo, essas atividades são particularmente importantes como dispositivo de promoção de saúde e de qualidade de vida, uma vez que a vivência das diversas práticas permite alcançar benefícios biológicos e sociais que desencadeiam resultados na manutenção da saúde como um todo, designadamente no nível da Saúde Mental nas instituiçóes ${ }^{13}$.

Em suma, a animação de idosos é uma metodologia que influencia o dinamismo da estrutura de acolhimento e o bem-estar social e emocional dos residentes e dos profissionais ${ }^{20,27}$. Atua como facilitadora no acesso a uma vida mais ativa e criativa, melhora as relaçóes de comunicação com os outros e estimula a vida mental, física e afetiva da pessoa idosa. Nesse desiderato, solicita a intervenção ativa dos residentes, tornando-os mais participativos, criando um sentimento de utilidade ao mesmo tempo que fomenta a socializaçãa ${ }^{23,25}$. 


\section{Método}

Tendo por base o objetivo delineado para a presente pesquisa, o estudo enquadra-se no paradigma geral da investigação qualitativa, de carácter exploratório ${ }^{28}$, no sentido em que visa compreender uma realidade que se situa perante conceitos como intervenção social e bem-estar e que pretende conhecer lógicas profissionais e vivenciais de sujeitos, as suas representaçốes e formas de ação, o que exige uma compreensão de sentidos de atuação $\mathrm{o}^{29,30}$.

Com efeito, nesse exercício de conhecimento do papel das atividades socioculturais nas estruturas residenciais para pessoas idosas, em uma circunstância tão específica como a que se vive hoje, pretende-se, sobretudo, perceber de que forma os mais frágeis são protegidos. Assim, objetiva-se com este estudo construir saber que poderá ser devolvido em forma de intervenção nas esferas política e social, ao possibilitar aos grupos um melhor conhecimento de si próprios, conhecimento que se pretende que transcenda o universo acadêmicó .

Para a recolha de dados, atendendo às características dos participantes e da situação atual de obrigatoriedade de isolamento social, privilegiou-se o inquérito por entrevista realizado por telefone. As entrevistas foram feitas pela investigadora do presente estudo com recurso a um guião semiestruturado ${ }^{28}$, em que as seis questóes, previamente formuladas, pressupunham respostas abertas. Interessou, com a aplicação das entrevistas aos sujeitos participantes, a descrição das realidades vividas, mas também o exercício reflexivo que fizeram sobre si mesmos e sobre as práticas que estão desenvolvendo ${ }^{30}$.

As entrevistas foram gravadas, posteriormente registradas em um suporte escrito e, por fim, tratadas com a técnica de análise de conteúdo ${ }^{30}$. Uma vez que a escolha da técnica mais adequada para analisar o material recolhido depende dos objetivos do estudo e do posicionamento paradigmático do investigador, nesta pesquisa foi utilizada a análise categorial que, tal como explica Bardin ${ }^{31}$, diz respeito à análise temática. Assim, a realização desse processo teve como eixos estruturadores o seguinte conjunto de momentos: após uma leitura atenta e profunda da entrevista, os enunciados foram segmentados em função dos temas (Constrangimentos e Modelos de Atuação) e das categorias (Reorganização do Quotidiano; Objetivos Norteadores; Novas Atividades; Novas Estratégias de Implementação; Continuidade dos Projetos) adotados previamente e que estavam refletidos no guião da entrevista. Em cada uma das categorias foram encontradas subcategorias - que tiveram por base os assuntos que mais frequentemente surgiram nas narrativas dos entrevistados - que facilitaram o processo interpretativo. Com essa decomposição dos dados foi construída uma grelha de análise, pela qual se realizou o processo de interpretação. Nesse sentido, e perante o apresentado, a análise por categorias constituiu-se como o elemento estruturador da análise de conteúdo, que de acordo com Bardin ${ }^{31}$ é uma das mais utilizadas em investigaçôes qualitativas. 
Em relação aos procedimentos éticos da investigação, salienta-se que no presente trabalho foram respeitadas as recomendaçôes no que se refere aos estudos que envolvem seres humanos constantes da Declaração de Helsínquia. Foi, também, solicitado a todos os sujeitos participantes, antes da realização da entrevista, autorização para proceder à pesquisa e todos assinaram um Termo de Consentimento Livre e Esclarecido (TCLE). A confidencialidade da identidade dos profissionais foi garantida mediante a utilização de letras e números para codificação dos entrevistados.

\section{Espaços e participantes}

Para a recolha de dados, a seleção das instituições foi feita por conveniência, obedecendo aos critérios de diversidade de práticas no âmbito das atividades explanadas no ponto anterior deste artigo. Assim, foram escolhidas 16 estruturas residenciais de apoio a pessoas idosas, situadas de norte a sul de Portugal Continental (Tabela 1), tendo sido entrevistados os técnicos que desempenham o papel de animadores de cada uma delas, perfazendo um total de 16 participantes (Tabela 2).

Tabela 1. Caracterização das estruturas residenciais

\begin{tabular}{|c|c|c|c|}
\hline & & Participan & \\
\hline & & $N=16$ & $\mathrm{~N}=\%$ \\
\hline \multirow{3}{*}{ Localização geográfica } & Zona Norte & 4 & 25 \\
\hline & Zona Centro & 9 & \multirow{2}{*}{$\begin{array}{l}56,25 \\
18,75\end{array}$} \\
\hline & Zona Sul & 3 & \\
\hline \multirow{2}{*}{ Natureza jurídica } & Entidade sem fins lucrativos & 11 & 68,7 \\
\hline & Entidade com fins lucrativos & 5 & 31,3 \\
\hline \multirow{4}{*}{ Número de clientes } & $<30$ & 2 & 12,5 \\
\hline & $31-50$ & 8 & 50 \\
\hline & $51-70$ & 4 & 25 \\
\hline & $71-90$ & 2 & 12,5 \\
\hline
\end{tabular}

Fonte: Elaborada pela autora

Tal como já foi referido, a escolha dessas instituiçóes teve como principal motivo a representatividade. Dessa forma, procuraram-se estruturas residenciais que pelas suas características - quer no que respeita à localização geográfica, à sua natureza jurídica e ao número de residentes - tivessem uma diversidade de práticas de ação que permitisse uma recolha de dados mais aprofundada e representativa.

Assim, e conforme se pode verificar na Tabela apresentada acima, no que se refere à localização geográfica, quatro estruturas residenciais estão situadas na zona norte de Portugal - designadamente nos distritos de Viana do Castelo, Aveiro e Viseu; nove são da zona centro - mais concretamente nos distritos de Leiria, Coimbra, Santarém e Lisboa; e três pertencem à zona sul do país - Faro e Évora. 
Quanto à natureza jurídica, 11 são entidades sem fins lucrativos, nomeadamente Instituições Particulares de Solidariedade Social, e cinco são instituições privadas, com fins lucrativos.

Quanto ao número de residentes, apenas duas têm menos de trinta clientes, oito têm entre 31 e cinquenta pessoas institucionalizadas e quatro têm entre 51 e setenta pessoas idosas residentes.

Em concordância com o que já foi referido no início deste ponto, foram entrevistados 16 técnicos que desempenham o papel de animadores, que constituíram o grupo de sujeitos participantes deste estudo e que são apresentados a seguir, na Tabela 2.

Tabela 2. Caracterização dos participantes

\begin{tabular}{|c|c|c|c|}
\hline & \multicolumn{3}{|c|}{ Participantes } \\
\hline & & $\mathrm{N}=16$ & $\mathrm{~N}=\%$ \\
\hline \multirow{2}{*}{ Sexo } & Feminino & 15 & 93,8 \\
\hline & Masculino & 1 & 6,2 \\
\hline \multirow{3}{*}{ Idade } & $25-29$ & 5 & 31,2 \\
\hline & $30-34$ & 8 & 50 \\
\hline & $35-40$ & 3 & 18,8 \\
\hline \multirow{2}{*}{ Nível de escolaridade } & Licenciatura & 14 & 87,5 \\
\hline & Mestrado & 2 & 12,5 \\
\hline \multirow{4}{*}{ Anos de experiência profissional } & $<3$ & 0 & 0 \\
\hline & $3-5$ & 8 & 50 \\
\hline & $6-8$ & 6 & 37,5 \\
\hline & $>9$ & 2 & 12,5 \\
\hline
\end{tabular}

Fonte: Elaborada pela autora

De acordo com os dados apresentados na Tabela acima, dos técnicos entrevistados, 15 são do sexo feminino e um do sexo masculino. No que se refere às idades, cinco detêm entre 25 e 29 anos, oito têm entre trinta e 34 anos e três apresentam entre 35 e quarenta anos de idade. Quanto ao nível de escolaridade, todos eles detêm licenciatura, sendo que dois possuem, inclusivamente, mestrado. No que se refere aos anos de experiência profissional, todos eles têm mais de três anos de experiência na área da animação de idosos, sendo oito trabalhando na área entre três e cinco anos, seis dos animadores têm entre seis e oito anos de experiência e dois dos profissionais apresentam uma experiência igual ou superior a nove anos. 


\section{Resultados e discussão}

Tomando por base o cruzamento da literatura científica com os resultados do trabalho empírico, nomeadamente com a análise de conteúdo das entrevistas semiestruturadas, os dados serão apresentados partindo das temáticas que emergiram, transversalmente, nos discursos dos participantes do estudo. Assim, serão colocados em relação os temas com as respetivas categorias e subcategorias, conforme apresentado no Quadro a seguir.

Quadro 1. Grelha de análise temática

\begin{tabular}{|c|c|c|}
\hline Tema & Categoria & Subcategoria \\
\hline \multirow{2}{*}{ Constrangimentos } & \multirow{2}{*}{ Reorganização do quotidiano } & Desempenho de novos papéis profissionais \\
\hline & & Reestruturação dos espaços \\
\hline \multirow{9}{*}{ Modelos de atuação } & Objetivos norteadores & Alteração dos objetivos \\
\hline & \multirow{3}{*}{ Novas atividades } & Ligação com as famílias \\
\hline & & Sensibilização para comportamentos preventivos \\
\hline & & Leitura do mundo e da situação atual \\
\hline & \multirow{4}{*}{ Novas estratégias de implementação } & Maior utilização das tecnologias \\
\hline & & Atividades individuais e em pequeno grupo \\
\hline & & Atividades de concretização autônoma \\
\hline & & Criação de materiais reutilizáveis (em segurança) \\
\hline & Continuidade dos projetos, com novas preocupações & Realização de atividades anteriormente planificadas \\
\hline
\end{tabular}

Fonte: Elaborada pela autora

Tal como se pode verificar na Tabela acima, emergiram dois grandes temas nos discursos dos sujeitos: os constrangimentos que essa nova situação provocou no que se refere ao desenvolvimento de atividades socioculturais nas estruturas residenciais e as alterações desencadeadas no nível dos modelos de atuação em contexto pandêmico.

De uma forma transversal, todos os sujeitos admitiram que os constrangimentos colocados ao seu trabalho estão diretamente relacionados com a reorganização que cada instituição teve de realizar, tendo os profissionais passado a assumir funções que anteriormente não eram da sua competência. Essa recolocação, prevista nas Orientações e Circulares Informativas da Direção-Geral da Saúde portuguesa, está relacionada com as medidas de prevenção e controle da infeção que cada estrutura residencial decidiu adotar, a fim de evitar, diminuir ou limitar o impacto da Covid-19, conforme vinculado na Orientação n. 009/2020 de 11/03/2020 $0^{32}$.

Nessa reorganização do quotidiano, a própria reestruturação dos espaços físicos dos equipamentos sociais trouxe implicaçôes no que concerne ao trabalho desenvolvido no âmbito da animação de idosos. Com efeito, para manter o distanciamento social e impedir cadeias de transmissão, todos os animadores admitiram que viram os espaços próprios de trabalho e as áreas comuns serem profundamente alterados. Tais alteraçôes não são vistas pelos técnicos como um elemento desmotivador, mas antes como uma contrariedade, consequência da situação atual, que obriga a novas formas de atuação. 
Assim, e na sequência do exposto, todos os técnicos referiram que tiveram de adotar novos modelos de atuação e novos objetivos de intervenção. A verdade é que, nesse contexto tão específico, acabaram por emergir novas atividades que todos os profissionais reconheceram como sendo prioritárias nesse momento. A primeira é a ligação com as famílias. Desde que a Orientação n. 009/2020 de 11/03/2020³1, da Direção Geral da Saúde, suspendeu as visitas a instituições nas quais residam pessoas idosas, o animador passou a salientar-se como interface entre a sua instituição, a pessoa idosa e sua família. Todos os sujeitos entrevistados admitiram que esse tipo de atividade - ligação e contacto com a família - passou a ser prioritário, bem como a procura da melhor forma de promover essa aproximação.

Em linha com o referido, e visando precisamente a segurança, a comunicação e a relação, todos os entrevistados admitiram ter introduzido nas suas planificaçóes atividades promotoras de proteção e de prevenção do risco de contágio. Segundo os profissionais, trabalhar esse tipo de informação permite criar espaços para a comunicação interpessoal23 ${ }^{23}$ levando a que os residentes se sintam mais calmos, mais seguros e também mais confiantes para manter as ligaçóes socioafetivas, quer com os outros residentes, quer com os profissionais ${ }^{7}$.

Nesse cenário, e conforme explicaram os entrevistados, o animador tornou-se a pessoa de referência para colocar questóes, para esclarecer dúvidas, para debelar medos, emergindo como mediador na leitura desse novo mundo e na vivência dessa nova situação. Por isso, as atividades realizadas no âmbito da animação de idosos ganharam outro enfoque, muito mais centrado na mediação de realidades ${ }^{17,26}$.

Nesses novos modelos de atuação, os técnicos perceberam que teriam de apostar em outros modos de implementar as atividades, procurando novas estratégias. Isso porque desde cedo os animadores perceberam que manter a interação social era fundamental para o bem-estar dos residentes e, em pleno contexto pandêmico, procuraram operacionalizá-la de forma virtual em uma lógica de sociabilidade digital, que encontrou na interatividade da internet e das aplicaçóes das redes sociais a possibilidade de amenizar os efeitos que a imposição do isolamento social e a proibição de visitas geraram ${ }^{13}$.

Assim, todos admitiram que, em uma procura para manter as interaçóes humanas e cumprindo as medidas gerais de proteção dos residentes, passou a existir uma utilização mais predominante das tecnologias. Computadores, tablets e telemóveis converteram-se em elementos fundamentais da práxis profissional dos técnicos dessas instituições. Desde filmagens a ligaçóes por videoconferência, a celebraçóes religiosas e a realização de atividades de cariz cultural e artístico, muitas foram as estratégias utilizadas ${ }^{22}$. Indo ao encontro do apresentado pelos entrevistados, as tecnologias ganharam um novo lugar nesses contextos institucionais.

Um outro aspeto destacado pelos entrevistados foi a aposta na criação de atividades que pudessem ser desenvolvidas de forma autônoma pelos residentes. Assim, as novas estratégias de implementação privilegiam o empowerment dos residentes, por uma ótica de eles se transformarem nos agentes e nos protagonistas das atividades de animação ${ }^{26,27}$. 
Ainda no que se refere às novas estratégias adotadas, os participantes do estudo sublinharam, também, a preocupação com a criação/adaptação de materiais passíveis de serem usados e reutilizados, cumprindo os cuidados de segurança e anulando o seu potencial de transmissibilidade do vírus. A adaptação dos materiais teve como principal objetivo permitir a realização de atividades em grupo (ainda que pequenas), uma vez que esse tipo de ação é fundamental para estabelecer as relaçôes sociais e a comunicação interpessoal ${ }^{23,27}$.

Ainda dentro do tema - modelos de atuação -, os profissionais referiram a importância de dar continuidade a atividades anteriormente planificadas, não só aquelas que vinham na sequência de projetos já iniciados, mas também atividades que favorecem a manutenção das rotinas em uma perspetiva de orientação no espaço e no tempo, evitando a desorganização e a confusão $0^{33}$. Assim, todos os entrevistados foram unânimes em admitir que continuaram a realizar atividades planificadas e iniciadas anteriormente à pandemia como forma de minimizar os impactos da reestruturação da vida quotidiana, desde que cumpridas todas as questóes de segurança.

Em jeito de síntese, as estruturas residenciais são a casa de quem lá habita. É o espaço onde as pessoas procuram segurança, mas sobretudo conforto e bem-estar. Esse tipo de instituição é de natureza coletiva, tendo, por isso, de atender às necessidades do grupo, mas também de acorrer às necessidades específicas de cada indivíduo. Se este trabalho já apresenta, em condições normais, grandes desafios, no contexto específico que vivemos atualmente esses desafios são ampliados.

Assim, e na sequência dos dados apresentados, fruto do trabalho empírico e do cruzamento com a literatura da especialidade, percebe-se que a pandemia trouxe grandes desafios às estruturas residenciais para pessoas idosas. Por acolherem aqueles que são potencialmente de maior risco, essas instituições se viram obrigadas a transformar o seu quotidiano em um equilíbrio difícil de proteção dos que lá vivem e trabalham e na manutenção da qualidade de vida e do bem-estar de quem lá vive.

Nesse sentido, e indo ao encontro do primeiro objetivo - identificar os constrangimentos ao desenvolvimento da animação de idosos no contexto específico atual -, os dados revelam que a Covid-19 originou alteraçôes profundas, levando à reorganização das instituiçóes (quer no nível dos recursos humanos, quer no nível dos espaços físicos) e das práticas de intervenção. Hoje, tudo é mais higienizado, mais afastado, mais assustador, mais difícil. Os contactos sociais foram alterados e as relaçóes sociais, profundamente modificadas.

Embora muitos técnicos tivessem assumido também outras funções dentro das estruturas residenciais, fruto da recolocação interna de recursos humanos, ao mesmo tempo que assistiram a uma transfiguração dos seus espaços de trabalho, a verdade é que todos os profissionais entrevistados foram unânimes em aceitar essas alteraçóes como sendo inevitáveis e, em um espírito de resiliência, procuraram a excelência das práticas de animação desenvolvidas.

Tendo essa procura da excelência como missão, os constrangimentos foram aceites e incorporados em um plano mais abrangente de intervenção social. Os profissionais apostaram em novos modelos de atuação, coerentes com os desafios contemporâneos. 
Dessa forma, e dando resposta ao segundo objetivo - conhecer as mais valias desse tipo de intervenção no bem-estar dos residentes e o seu papel na prevenção e controle da Covid-19 dentro das instituiçóes -, os dados revelam que os técnicos apostaram na alteração dos objetivos e das práticas, indo ao encontro das necessidades do momento. Conscientes de que as pessoas idosas com quem trabalham estão mais propensas a alterações emocionais motivadas pelo distanciamento social, pela ansiedade, pelo medo de contaminação e, inevitavelmente, do desconhecido ${ }^{34}$, os animadores construíram planos de ação estruturados para diferentes cenários, baseados em diversas estratégias. Para além de continuarem preocupados em fomentar as capacidades sociais e cognitivas, os profissionais entenderam a importância de serenar os residentes, a fim de que eles se sentissem bem, apoiados e incluídos no espaço ${ }^{26,33,34}$, em uma lógica de bem-estar coletivo. Nessa equação, as relações interpessoais são fundamentais e os animadores passaram a privilegiar o papel de mediadores, quer no tocante às famílias, quer aos próprios residentes e colaboradores ${ }^{14}$. Conforme se pode ver pelos resultados deste estudo, os entrevistados admitiram a importância de se realizarem atividades socioculturais, objetivando as sociabilidades ${ }^{13,33,34}$, quer desenvolvendo ações que não estavam anteriormente previstas (designadamente, no âmbito da prevenção do risco de transmissão do vírus), quer dando continuidade a projetos já existentes. Em ambas as situações, a forma de implementação teve de ser repensada, obrigando o animador a realizar constantes exercícios de criatividade ${ }^{20,25}$. Percebe-se que os projetos de animação são, hoje mais do que nunca, ferramentas imprescindíveis de bem-estar emocional e social ${ }^{11,21}$, desenvolvendo práticas pluridisciplinares de Saúde Mental e física.

Por fim, retomamos o principal objetivo que norteou este estudo e que pretendeu perceber se a realização de atividades socioculturais, por meio da animação de idosos, pode funcionar como interface do bem-estar emocional dos residentes e da prevenção da transmissão da Covid-19, segundo os técnicos que desempenham o papel de animadores. Conforme os dados apurados, a realização de atividades socioculturais é fundamental em contextos de institucionalização permanente de pessoas idosas ao minimizar o risco de depressão e de regressão das capacidades sociais e cognitivas, devido aos muitos fatores estressantes, por exemplo, o afastamento de familiares e pessoas significativas, a incerteza da duração de tal situação e aos diversos contornos que ela encerra ${ }^{13}$. Não é por isso de estranhar que as estruturas residenciais atuais, muito pressionadas pela necessidade de distanciamento social ${ }^{13}$, acabem por se transformar em ambientes nocivos com elevado risco para o desencadeamento de distúrbios mentais, originando transtorno de ansiedade e depressão, com impacto direto na qualidade de vida ${ }^{19,34}$.

Nesse quadro, os dados da presente pesquisa são consentâneos com o encontrado na literatura científica produzida sobre essa temática. Sobretudo no contexto específico aqui estudado, as atividades socioculturais parecem funcionar como elementos estruturantes na promoção da Saúde Mental e no bem-estar coletivo ${ }^{2,18,34}$. Para além de possibilitarem o estabelecimento de rotinas (e o trabalho de orientação), essas atividades são fundamentais para o relaxamento, a sociabilização e a reflexão ${ }^{13,33}$. Inseridos em um contexto extremamente assustador, de afastamento físico dos pares, dos colaboradores da instituição e dos familiares, as pessoas idosas residentes encontram na animação práticas 
que favorecem a melhoria da qualidade de vida. Segundo os profissionais, principalmente nesse período de exceção, a animação de idosos demarca-se no aumento das solidariedades e das sociabilidades comunitárias, contrariando o risco de isolamento e solidão ${ }^{11,21}$. Com efeito, todos os animadores admitiram que no centro do seu agir profissional está a preocupação com a criação de laços e vínculos que liguem as pessoas a si próprias e aos outros significativos.

Porque o ser humano não é somente biofísico, mas também psicossocial2, enquanto durar o distanciamento social e as medidas de mitigação da pandemia, que são particularmente difíceis em contextos de institucionalização, as atividades socioculturais promotoras de relaçốes interpessoais e de bem-estar pessoal e coletivo são fundamentais, tal como é defendido nas mais recentes investigaçôes no campo da Saúde Mental ${ }^{13,34}$.

Para além de fomentar o encontro, promover novas abordagens de vivência e compreensão entre as pessoas ${ }^{23,24,27}$, os dados também revelam que as atividades socioculturais podem constituir-se em poderosos instrumentos preventivos da Covid-19, ao sensibilizar e elucidar para os riscos de contágio e ao prevenir comportamentos de risco, amenizando as consequências do isolamento social e, entretanto, das medidas tomadas nas instituiçôes ${ }^{13,18}$.

Em suma, a animação, como estratégia de interface entre saúde e práticas socioculturais, revela-se fundamental na conjuntura vivencial atual das estruturas residenciais para pessoas idosas, sendo decisiva para lidar com esse cenário desafiante e assustador.

\section{Conclusões}

As pessoas idosas apresentam maior letalidade em relação à Covid-19, sendo, concomitantemente, o grupo social mais vulnerável nesse contexto pandêmico ${ }^{2}$. Ao longo deste estudo, tentou-se perceber se em um contexto de crise, como o que existe atualmente nas estruturas residenciais para pessoas idosas, em que se vive o dia a dia pensando na sobrevivência, faz sentido realizar atividades socioculturais, designadamente no âmbito específico da animação de idosos. Assim, e tendo consciência de que compreender esse fenômeno é analisá-lo como uma experiência humana, tendo por base as representaçôes dos profissionais de animação, os dados obtidos permitem entender que a intervenção social realizada pela animação de idosos detém um papel de primordial importância no bem-estar desses residentes, ao criar espaços de serenidade e momentos significativos de encontro consigo próprios e com os outros, em um quadro desafiante de pandemia.

A animação de idosos ajuda a debelar os obstáculos advindos dessa situação específica e, ao proporcionar a realização de atividades de desenvolvimento pessoal e social, combate situações de dependência física e descompensação psíquica provocadas pelo estreitamento de horizontes, de interesses e de relações pessoais ${ }^{5,20,21}$. Hoje, mais que nunca, as atividades de animação de idosos - quotidianas/práticas, sociais, artísticas, intelectuais e espirituais/religiosas - contribuem para um clima de relacionamento saudável entre os residentes e entre eles e os colaboradores e os familiares. Na verdade, o plano de atividades, alterado em função daquilo que são as exigências do momento, 
dá ainda maior destaque àquele que foi sempre o princípio norteador: dar significado ao presente, utilizando a animação como plataforma de aproximação, vinculação e bem-estar. Por isso, e conforme revelam os dados deste estudo, pensar e adaptar orientaçóes para a eficácia no combate ao surto é muito mais que promover o isolamento social, é trabalhar em uma abordagem muito mais voltada para a criação de estratégias de suporte social, de promoção do bem-estar emocional e manutenção da Saúde Mental, em que as atividades socioculturais detêm um papel fundamental.

\section{Conflito de interesse}

A autora não tem conflito de interesse a declarar.

\section{Direitos autorais}

Este artigo está licenciado sob a Licença Internacional Creative Commons 4.0, tipo BY (https://creativecommons.org/licenses/by/4.0/deed.pt_BR).

(cc) BY

Editora

Elizabeth Maria Freire de Araújo Lima

Editora associada

Lina Rodrigues de Faria

Submetido em

$11 / 08 / 20$

Aprovado em

$06 / 06 / 21$

\section{Referências}

1. Lisboa. Serviço Nacional de Saúde. Temas da saúde - Covid-19 [Internet]. Lisboa: Serviço Nacional de Saúde; 2020 [citado 23 Jul 2020]. Disponível em: https://www. sns24.gov.pt/tema/doencas-infecciosas/covid-19/\#sec-0

2. Hammerschmidt K, Bonatelli L, Carvalho A. Caminho da esperança nas relaçôes envolvendo os idosos: olhar da complexidade sobre pandemia da Covid-19. Texto Contexto Enferm. 2020; 29:e20200132. Doi: https://doi.org/10.1590/1980-265XTCE-2020-0132.

3. Dumazedier J. Sociologia empírica do lazer. São Paulo: Perspetiva; 2004.

4. Hall S. The centrality of culture: notes on the cultural revolutions of our time. In: Thompson K, organizador. Media and cultural regulation. London: Thousand Oaks; 1997. p. 207-38. 
5. Sequeira C. Cuidar de idosos com dependência física e mental. Lisboa: Lidel; 2018.

6. Espírito-Santo H, Daneil F. Introdução a trajetos do envelhecimento: perspetivas teóricas e empíricas. Coimbra: Imprensa da Universidade de Coimbra; 2019. p. 7-11. Doi: https://doi.org/10.14195/978-989-26-1737-4.

7. Fonseca A. Boas práticas de ageing in place. Divulgar para valorizar. Guia de Boas Práticas [Internet]. Lisboa: Fundação Calouste Gulbenkian e Faculdade de Educação e Psicologia, Universidade Católica Portuguesa; 2019 [citado 1 Ago 2020]. Disponível em: https://content.gulbenkian.pt/wp-content/uploads/2018/05/15122919/ageing _ in_place_web.pdf

8. Pani-Harreman K, Gerrie B, Inés Z, Gertrudis K, Joop D. Definitions, key themes and aspects of 'ageing in place': a scoping review. Ageing Soc. 2020; 1-34. Doi: https://doi. org/10.1017/S0144686X20000094.

9. Halaweh H, Synneve D, Ulla S, Carin W. Perspectives of older adults on aging well: a focus group study. J Aging Res. 2018; 1-9. Doi: https://doi. org/10.1155/2018/9858252.

10. Ennuyer B. La discrimination par lâge des «personnes âgées»: conjonction de représentations sociales majoritairement négatives et d'une politique vieillesse qui a institué la catégorie «personnes âgées» comme posant problème à la société. Rev Droits L'homme. 2020; (17):1-18. Doi: https://doi.org/10.4000/revdh.8756.

11. Luísa C. Teorias leigas em pessoas idosas - um guia para educadores sociais e cuidadores. Viseu: Psicosoma; 2017.

12. Capucha L. Envelhecimento e políticas sociais em tempos de crise. Sociol Problemas Prat. 2014; (74):113-31. Doi: http://dx.doi.org/10.7458/SPP2014743203.

13. Ribeiro O, Santana G, Tengan E, Silva L, Nicolas E. Os impactos da pandemia da Covid-19 no lazer de adultos e idosos. Licere. 2020; 23(3):391-428. Doi: doi. org/10.35699/2447-6218.2020.25456.

14. Murillo I. La vivienda en la vejez: problemas y estrategias para envejecer en sociedad. Madrid: Editorial CSIC; 2019.

15. Lisboa. Segurança Social. Apoios sociais e programas [Internet]. Lisboa: Segurança Social; 2020 [citado 26 Jul 2020]. Disponível em: http://www.seg-social.pt/idosos

16. World Health Organization. World report on ageing and health [Internet]. Geneva: WHO; 2015 [citado 30 Jun 2020]. Disponível em: https://apps.who.int/iris/bitstream/ handle/10665/186463/9789240694811_eng.pdf;jsessionid=290AE63E4ABF26CBAE 1F6D98654DD48F? sequence $=1$

17. Lisboa. Direção-Geral da Saúde. Estratégia nacional para o envelhecimento ativo e saudável 2017-2025 [Internet]. Lisboa: Direção-Geral da Saúde; 2017 [citado 29 Jun 2020]. Disponível em: https://www.sns.gov.pt/wp-content/uploads/2017/07/ENEAS.pdf

18. Moraes E, Viana L, Resende L, Vasconcellos L, Moura A, Menezes A, et al. Covid-19 nas instituições de longa permanência para idosos: estratégias de rastreamento laboratorial e prevenção da propagação da doença. Cienc Saude Colet. 2020; 25(9):3445-58. Doi: http://dx.doi.org/10.1590/1413-81232020259.20382020.

19. Faro A, Bahiano M, Nakano T, Reis C, Silva B, Vitti L. Covid-19 e saúde mental: a emergência do cuidado. Estud Psicol. 2020; 37:e200074. Doi: https://doi. org/10.1590/1982-0275202037e200074.

20. Jacob L. Animação de idosos. Porto: Legis; 2013. (Coleção Geriatria e Gerontologia). 
21. Sousa J. Institucionalização de pessoas idosas e adaptação ao quotidiano institucional: qual o papel da animação sociocultural? Quad D’animació Educ Soc [Internet]. 2018 [citado 18 Jun 2020]; (28):1-32. Disponível em: http:/quadernsanimacio.net/ ANTERIORES/veintiocho/index_htm_files/Institucionalizacao.pdf

22. Ventosa V. Metodologia e recursos musicais para animar o ócio na terceira idade. In: Pereira J, Lopes M, Rodrigues T, organizadores. Animação sociocultural, gerontologia e geriatria - a intervenção social, cultural e educativa na terceira idade. Chaves: Intervenção; 2013. p. 139-55.

23. Delgado C, Rosanna B. O papel dos projetos de animação sociocultural com idosos institucionalizados [Internet]. In: Aurízia A, organizador. Envelhecer no Algarve. Faro: Universidade do Algarve; 2018 [citado 18 Jun 2020]. p. 152-66. Disponível em: http:// geronte.pt/pdf/Envelhecer_no_Algarve.pdf

24. Pertuz M. Tres miradas sobre la vejez: desde el psicoanálisis, la gerontagogía y la educación social. Palobra. 2018; 18:20-32. Doi: https://doi.org/10.32997/2346-2884vol.0-num.18-2018-2205.

25. Queirós N. Anim’arte - jogos e técnicas de animação para idosos. Lisboa: Coisas de Ler; 2015.

26. Quintero J. La animación sociocultural como enfoque de intervención comunitaria con el adulto mayor. Poiésis. 2017; 33:15-20. Doi: https://doi. org/10.21501/16920945.2492.

27. Sousa J. Intervenção na saúde mental: a animação comunitária no processo de reabilitação psicossocial”. In: Fontes A, Sousa J, Lopes MSP, Mónico S, organizadores. Intervenção em contextos socioculturais e educativos. Lisboa: Coisas de Ler; 2017. p. 25-44.

28. Flick U. Introdução à metodologia de pesquisa: Um guia para iniciantes. Porto Alegre: Penso; 2013.

29. Carlin A, Younhee $\mathrm{H}$. Teaching qualitative research: versions of grounded theory. Grounded Theory Rev. 2019; 18(1):29-43.

30. Bourdieu P. La ilusión biográfica. Rev Acta Sociol. 2011; 156:121-8. Doi: http://dx.doi. org/10.22201/fcpys.24484938e.2011.56.29460.

31. Bardin L. Análise de conteúdo. Lisboa: Ediçóes 70; 2004.

32. Lisboa. Direção-Geral da Saúde. Orientação no 009/2020, de 11de Março de 2020 [Internet]. Lisboa: Direção-Geral da Saúde; 2020 [citado 13 Jun 2020]. Disponível em: https://www.dgs.pt/directrizes-da-dgs/orientacoes-e-circulares-informativas/orientacaon-0092020-de-11032020.aspx

33. Silva H, Santos L, Oliveira A. Efeitos da pandemia no novo Coronavírus na saúde mental de indivíduos e coletividades. J Nurs Health. 2020; 10(4):1-10. Doi: 10.15210/ jonah.v10i4.18677.

34. Alves A, Magalhães I. Implicaçôes na saúde mental de idosos diante do contexto pandêmico da Covid-19. REAID. 2020; 93:e020005. Doi: https://doi.org/10.31011/ reaid-2020-v.93-n.0-art.774. 
Around $40 \%$ of Covid-19 deaths in Portugal have occurred in nursing homes, resulting in the implementation of social isolation measures, with grave consequences for the mental health of residents. This exploratory study aimed to explore whether performing sociocultural activities designed to cheer up the elderly during the pandemic works as an interface between emotional well-being and the prevention of Covid-19 transmission, from the viewpoint of the professionals performing the activities. We present the findings of a content analysis of semi-structured interviews conducted with 16 professionals working in nursing homes in continental Portugal. The findings show that performing sociocultural activities is a determining factor in the well-being and quality of life of nursing home residents.

Keywords: Old age. Institutionalization. Covid-19. Sociocultural intervention. Emotional well-being.

En Portugal, casi el 40\% de las muertes por Covid-19 tuvieron lugar en instituciones para ancianos, pasando a que se les exigieran prácticas institucionales de aislamiento social, con graves repercusiones en la salud mental de los residentes. Con esta investigación, cualitativa y exploratoria, se pretendió percibir si, en el período de pandemia, la realización de actividades socioculturales, por medio de la entretención de ancianos, puede funcionar como interfaz del bienestar emocional de los residentes y de la prevención de la transmisión de la Covid 19, según los técnicos que desempeñan el papel de entretenedores. De tal forma, se presentan los resultados obtenidos a partir del análisis de contenido de la entrevista semiestructurada realizada con 16 profesionales que trabajan en estructuras residenciales para ancianos de norte a sur de Portugal Continental, habiendo los datos dejado claro que la realización de actividades socioculturales surge como elemento determinante del bienestar y de la calidad de vida de las personas que viven en esas instituciones.

Palabras clave: Vejez. Institucionalización. Covid-19. Intervención sociocultural. Bienestar emocional. 